\title{
User Guidance for Document-Driven Processes in Enterprise Systems
}

\author{
Stefan Morana ${ }^{1}$, Silvia Schacht ${ }^{2}$, Ansgar Scherp $^{3}$, and Alexander Mädche ${ }^{1,2}$ \\ ${ }^{1}$ Institute for Enterprise Systems, University of Mannheim, Germany \\ morana@es . uni-mannheim. de \\ ${ }^{2}$ Chair of Information Systems IV, Business School, University of Mannheim, Germany \\ \{schacht, maedche\} @es. uni-mannheim.de \\ ${ }^{3}$ Research Group Data and Web Science, University of Mannheim, Germany \\ ansgar@informatik.uni-mannheim.de
}

\begin{abstract}
In practice up to $80 \%$ of the overall processed data is only available in an unstructured form, such as documents. The handling of documents within organizations is still an issue in both, research and practice. Employees perceive the way to handle business-relevant documents as high effort and struggle with handling documents compliant to organizational standards. As a result documents become decoupled from the defined business processes and scattered all over the organizations IT landscape. Understanding users and their needs in order to increase their intention to use Enterprise Systems consistent to organization-wide business processes is a gap in the existing literature. This paper presents a design science research project focusing on user guidance for document-driven processes in Enterprise Systems. Building on existing research in user guidance, we suggest to increase the user's individual awareness towards processing documents consistent to organizational processes. In addition to our research design, we present a preliminary artifact version based on the results of an exploratory interview study.
\end{abstract}

Keywords: Enterprise Systems, Enterprise Content Management, User Guidance, Intention to Use.

\section{Introduction}

Enterprise Systems (ES) offer a comprehensive set of functional modules that are generally based on industry best practices [1]. In contrast to traditional information systems (IS), ES target large-scale integration of data and business processes across a company's functional areas [2]. In the literature, the term ES is often used synonymously with Enterprise Resource Planning (ERP) application software focusing on streamlining business processes and the associated structured data. This rather transaction- and process-oriented perspective has been extended with packages targeting large-scale integration of structured and unstructured information and people. Accordingly, the term ES has grown to refer to all large organization-wide packaged applications, also including systems such as, Customer Relationship Management, Data 
Warehouses and Business Intelligence, Enterprise Content Management (ECM), Portals, Groupware, and application components of the software platform such as application servers or Business Process management engines on which these application systems are built [3].

In practice up to $80 \%$ of the overall processed data is only available in an unstructured form [4]. In particular, employees use, create and store different types of documents such as offers, invoices, contracts and others as part of their work practices. Ideally, the organization-wide defined business processes and the work practices should go hand in hand. However, due to complexity and lack in understanding of organization-wide business processes, a divergence can be observed in reality. Thus, documents are filed at many places, but often not at those locations where the organization intends them to be stored. Documents become decoupled from the defined business processes and scattered all over the organizations IT landscape. In order to prevent such scattering of documents containing information, which may be crucial for organizations [5], many companies have implemented technologies like Enterprise Content Management systems (ECMS) [6] supporting their employees in managing documents. ECM has also risen interested in research, subsuming studies on Content Management in general and Document Management in specific [7] . Some researchers also settle ECM into the field of Knowledge Management (KM), “...since ECMSs can be used to capture and utilize content that contains explicit knowledge in repositories or to manage organizational knowledge resources"[8], p. 2.

However, most existing research on ECM concentrates their work on the architecture of ECMS and their capabilities. Some researchers study the implementation of ECMS from a strategic perspective (e.g. [6]), while others like vom Brocke et al. [9] focus on a general business-process oriented approach to ECM or observe users' acceptance of ECMS (e.g. [10]) independent from business processes. An essential element that is missing in existing research is addressing the users and their needs in order to increase their intention to use ECMS, or more general ES for document handling, consistent to organization-wide defined business processes. We believe that this is an important factor to be investigated and suggest addressing the identified research gap by the following research question:

How to increase individuals' intention to use Enterprise Systems in order to decrease their effort in handling documents and being compliant to organizational process standards?

The remainder of this paper is structured as following: Section 2 presents the methodological foundations of our research following a design science research approach. In the subsequent section, we describe the identified problem. In Section 4, we sketch a preliminary solution proposal for the identified issues. Finally, we conclude the paper with a short summary and an outlook on future work.

\section{Methodology}

In order to answer our research question, we follow the design science research approach as described by [11]. Figure 1 shows the general design cycle taken from [11] and its adaption for the research project. 
In the first cycle, we define and specify our overall research goal. Therefore, we plan to conduct both, a literature study and a case study in order to increase theoretical and practical relevance of our work. In doing so, we aim at getting a clear picture on the state of the art of existing studies and the issues of a case company related to document-handling. As a result of this first cycle, we intend to get an impression of a possible software solution to support users in the usage of ECMS, being compliant to organizational process standards, in the form of a mockup-based prototype. The second cycle focusses on the creation of a solution for the issues in documenthandling. Through an intensive user study, we extract concrete design principles that may support individuals to use the ECMS in a business compliant manner with less effort. The artifact of the second cycle will be a testable software solution including instantiation of our discovered design principles. The third and last cycle serves for the evaluation and refinement of our design principles. An instantiation of our principles in form of a software artifact will be introduced in the case company and users' intention to use the ECMS and their satisfaction will be measured. We finalize our research work by developing a design theory on effective and efficient documenthandling.

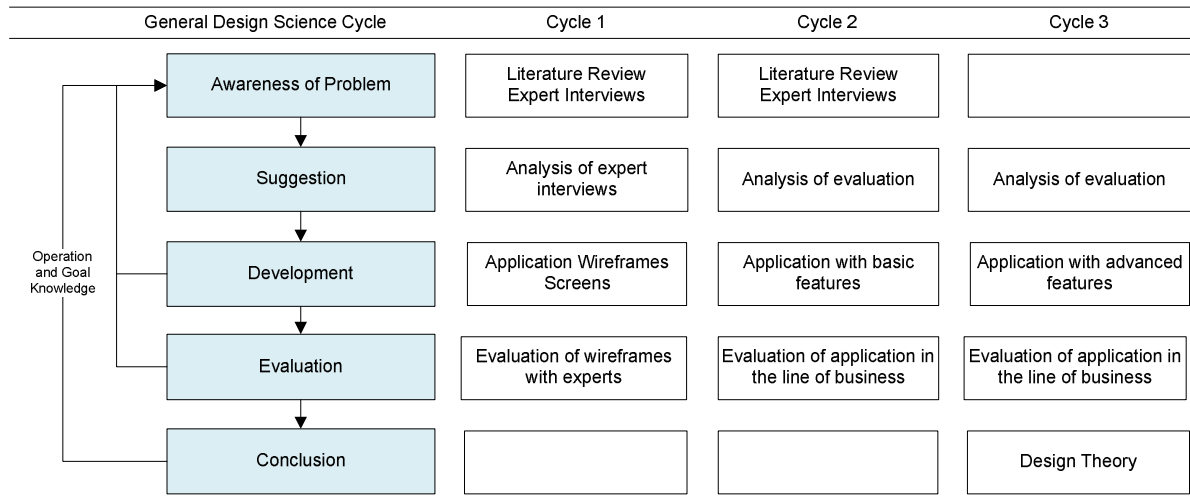

Fig. 1. Design Science Research project in three cycles (adopted from [12])

Our research is done in cooperation with a large manufacturing company. The company is a global supplier, development and service partner for customers of many various sectors such as automotive, civil aviation, and mechanical engineering. In 2011, the company had 12,630 employees in over 45 sites all over Europe and America and sales of more than 1.6 billion $€$. Since the company is aware of the document management challenges, a joint research project has been started. This enables us to observe individuals' usage behavior directly when using ECMS and triangulate data collection by document analysis and interviews [13]. Furthermore, in subsequent cycles of the design cycle we will have the opportunity to introduce and evaluate the artifact in a real-world environment. 


\section{Awareness of the Problem}

We have conducted a series of informal, illustrative expert interviews with eight, selected users to gain an understanding of the issues on document handling in the case company. One researcher carefully selected the interviewees according to their job description and dependency on ECMS. All interviewees possess various functions in the corporate procurement department of the case company. We perceive the corporate procurement department as representative since many processes of this department highly depend on actual, consistent and complete information captured in documents. Compared to other departments, we assume a higher intention of individuals to use ECMS in order to meet user's requirements on work-related documents by avoiding scattered documents. The interviews were guided by the central question of current issues in handling relevant documents. On average, each interview lasted 15 minutes. With interviewees' consent, we have recorded the interviews that were subsequently transcribed. The resulting documents were coded by one researcher using MaxQDA - a software application for qualitative data analysis. In order to code the interviews, we implemented an inductive coding approach aiming to extract those statements of the interviewees that were mentioned frequently and thus, seemed to be a key issue of them [14]. These issues have been analyzed and aggregated to similar issues.

Within the interviewee series, three topics arose frequently. Most interviewees (six out of eight) perceive the scattering of documents as a main issue of company-wide document handling. Because the company is distributed in multiple sites over Europe and America, various ES are used to handle documents and are implemented in different departments. In order to exchange the documents between the departments, employees are forced to create media disruptions resulting in increased paper-based documents and inconsistent document filing. One interviewee said: "Invoices are displayed in the system called WebCycle, but we need to print them [...]. Then, it has to be captured and edited in our SAP application. Finally, the paper-based document needs to be filed in our folders."

Another challenge often mentioned by interviewees is the lack of guidance. The case company has implemented a bundle of ES and recommends using these systems. As stated in Grahlmann et al. [8], the case company's ECMS consist of multiple technological components. There is no clear guidance how the users have to handle the documents in which system(s). Thus, one interviewee called for some "...guidance, claiming the system which needs to be used in a particular business process step."

Even if employees know where to file their documents according to company's business processes at a particular point of time, new or modified processes due to changing requirements like governmental regularities also hamper a consistent document management. One interviewee substantiated this impediment by insufficient communication. She stated: "Our main challenge is the currency of our documents. If there are some novelties, it is difficult to keep our documents up to date since the communication of such novelties tends to be zero. Often we realize such novelties only accidentally." 
All these issues result in an increased effort in handling relevant documents, which in turn leads to a higher reluctance of users to proceed daily work compliant to business processes. In order to reduce the effort of document handling, one interviewee summarized the requirements as following: "A system needs to be user friendly and enable one to store the documents centrally. Furthermore, all departments should be able to access the documents - if they need to access them - via a consistent user interface. In consequence, all those who are accessing the documents are responsible to keep the documents up-to-date [...] using standards defining where to store which documents accordingly."

Summarizing, we realized three key issues discussed by the interviewees: (1) users perceive the way they need to handle business-relevant documents as high effort, (2) users are dissatisfied with the usability of company's ECMS, and (3) users do not know the processes they need to follow in order to handle documents compliant to organizational standards.

\section{Solution Proposal}

There are probably multiple solutions for the issues stated above. One possible solution was mentioned by an interviewee: guidance. User guidance supporting individuals in their decision of work-related actions has been intensively researched in the past. Scherp [15], for example, researches user guidance when using a highlyinteractive, multimedia system called GenLab by providing a tutoring system. Others like Silver [16] study the phenomenon of decisional guidance. In his work, he provides an overview on situations when to implement decisional guidance, its opportunities, design and consequences. Building on this, Todd and Benbasat [17] research on influencing factors of individuals' decision behavior in order to manipulate their effort of decision making using guidance in Decision Support Systems.

Inspired by research in the field of decisional guidance, we belief that providing guidance to users increases the individual's awareness towards processing documents consistent to organizational processes. This increased process-awareness in turn may encourage users to handle documents more compliant to organization-wide defined business processes standards. Finally, the suggested guidance may lead to an increased intention to use of the ECMS and decrease scattering of documents. Building on this work, we propose that guiding employees can be a solution to the presented problem. Figure 2 sketches a preliminary view on the planned artifact. It is inspired by prior work on capturing and sharing best-practices in knowledge intensive activities and synchronizing them with the organizational business processes [18].

The principal goal of the artifact is the support of users in handling documents in their business processes compliant to organizational standards. The artifact builds on a set of preliminary meta-requirements (MRs) derived from the interviews and existing research. The first MR is the visual depiction of business process steps with guiding information. As shown in the left hand side of Figure 2, the software artifact provides information about the best-practices for executing a specific process, here the "purchase of raw iron". A process consists of a set of consecutive activities. 
The current activity is highlighted, in our example the metal purchase request in SAP. Buttons and links connect the activity with the ES used for accomplishing the activity. This allows the software artifact to seamlessly connect the work practices of the individual knowledge workers to the IT-supported organization's processes. In our example, a specific SAP ERP transaction is required for the metal purchase. Finally, activities can consist of sub-activities. Sub-activities that are executed repeatedly within a specific activity are worth to be captured explicitly in our artifact.

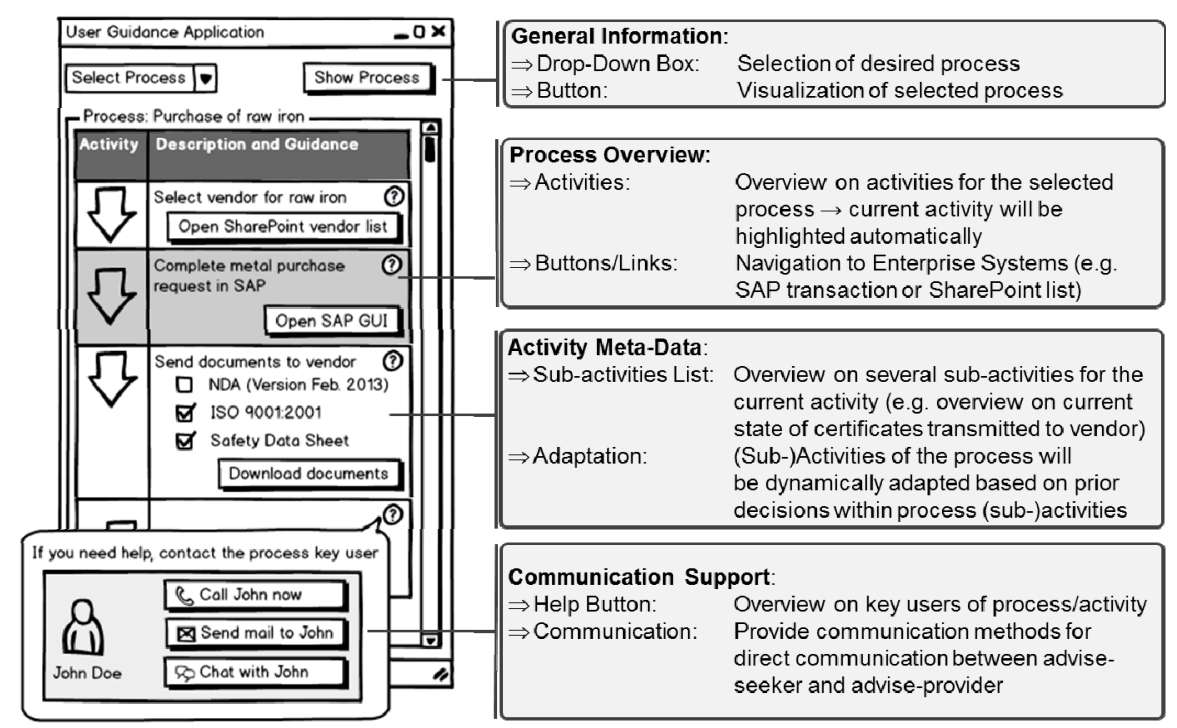

Fig. 2. Process guidance application (runs on user's desktop parallel to existing applications)

The second MR is the possibility to communicate with key users of the process. Individual activities can be connected with key users who can be contacted to obtain support for situations where the activity descriptions are not sufficient.

The third MR is the capturing of individual (best) practices. The users can arbitrarily modify the order of the activities in the processes. For example, when they experience a situation where the currently captured best-practice deviates from the actual process execution, e. g., when there are changes in the process flow due to legislative changes, updates of the ES, or just specific requirements of a customer. To modify the processes, the users can add new or change or delete existing activities. A key feature of our software artifact will be that such modifications during the execution of a process do not affect other concurrently executed processes [18]. Finally, the modifications made by the users can be incorporated again as best-practices and thus shared and communicated with the co-workers. This flexible management of processes, activities, and subactivities in our software artifact is achieved by using a specific ontology-based, contextualized representation of the process executions and their models [19].

The implementation of the software artifact will be developed as standalone desktop application. This application will provide ES connectors for our case company. As 
depicted in Figure 2, the application follows a side panel approach. This enables the guidance application to be displayed next to the existing applications currently used by the employees. By this, context switches between different applications are minimized or even eliminated.

\section{Conclusion}

This paper presents a design science research project focusing on user guidance for document-driven processes in Enterprise Systems. Building on existing research in user guidance, we suggest to increase user's individual's awareness towards processing documents consistent to organizational processes. The suggested artifact of user guidance aims to increase intention to use the ECMS and thus decrease the scattering of documents.

We are aware that the presented research-in-progress comes with several limitations. Since the presented research is a work in progress, our preliminary interview study primarily served for getting a first problem awareness within the case company. In order to increase validity and reliability of our research, we plan to conduct a comprehensive study covering a systematic sample of ECMS users and experts of the case company. Based on the results of this interview study, we plan to refine meta-requirements and derive design principles of our proposed solution. These design principles will be translated in concrete design decisions that will be implemented in a running software artifact as described. Subsequently, we plan to pilot our artifact within the case organization. Finally, we will evaluate the effects of our software intervention with regard to users' behavioral intention to use the ECMS and their satisfaction. In order to measure the change of individuals' usage behavior, we plan to apply the IS success model [20] as a foundation of our measurement model. Since we also perceive the necessity of a distinction between individuals' attitudes about the system and their attitudes about using the system, we plan to adapt the extended IS success model by Wixom and Todd [21].

We are convinced that our research can contribute to both, theoretical and practical aspects in the context of providing user guidance for document-intensive processes. From a theoretical perspective, our research aims to increase the existing body of knowledge on ES design by studying the interplay between organization-wide business processes and individual practices in the context of document processing. In contrast to existing ECMS research, our work will focus on users, their requirements and satisfaction when using ECMS enriched with guidance. On the other hand, our work contributes to practice, since our design principles can provide guidance on how to design software solutions in order to enable individuals to handle documents compliant to company's processes.

\section{References}

1. Markus, M.L., Tanis, C., van Fenema, P.C.: Enterprise resource planning: multisite ERP implementations. Communications of the ACM 43, 42-46 (2000)

2. Devadoss, P.R., Pan, S.L.: Enterprise systems use: Towards a structurational analysis of enterprise systems induced organizational transformation. Communications of the Association for Information Systems 19, 352-385 (2007) 
3. Seddon, P.B., Calvert, C., Yang, S.: A multi-project model of key factors affecting organizational benefits from enterprise systems. MIS Quarterly 34, 305-328 (2010)

4. Murthy, K., Deshpande, P.M., Dey, A., Halasipuram, R., Mohania, M., Deepak, P., Reed, J., Schumacher, S.: Exploiting Evidence from Unstructured Data to Enhance Master Data Management. Proceedings of the VLDB Endowment 5, 1862-1873 (2012)

5. Morschheuser, S., Raufer, H., Wargitsch, C.: Challenges and solutions of document and workflow management in a manufacturing enterprise: a case study. In: 29th Hawaii International Conference on System Sciences, vol. 5, pp. 4-12. IEEE (1996)

6. Nordheim, S., Päivärinta, T.: Implementing enterprise content management: from evolution through strategy to contradictions out-of-the-box. European Journal of Information Systems 15, 648-662 (2006)

7. O'Callaghan, R., Smits, M.: A strategy development process for enterprise content man-agement. In: ECIS 2005 Proceedings, pp. 1271-1282 (2005)

8. Grahlmann, K.R., Helms, R.W., Hilhorst, C., Brinkkemper, S., van Amerongen, S.: Reviewing Enterprise Content Management: a functional framework. European Journal of Information Systems 21, 268-286 (2011)

9. vom Brocke, J., Simons, A., Cleven, A.: Towards a business process-oriented approach to enterprise content management: the ECM-blueprinting framework. Information Systems and e-Business Management 9, 475-496 (2011)

10. Wiltzius, L., Simons, A., Seidel, S.: A Study on the Acceptance of ECM Systems. In: Wirtschaftinformatik Proceedings 2011 (2011)

11. Kuechler, B., Vaishnavi, V.: On theory development in design science research: anatomy of a research project. European Journal of Information Systems 17, 489-504 (2008)

12. Takeda, H., Veerkamp, P.: Modeling Design Processes. AI Magazine 11, 37-48 (1990)

13. Benbasat, I., Goldstein, D.K., Mead, M.: The Case Research Strategy in Studies of Information Systems. MIS Quarterly 11, 369-386 (1987)

14. Thomas, D.R.: A General Inductive Approach for Analyzing Qualitative Evaluation Data. American Journal of Evaluation 27, 237-246 (2006)

15. Scherp, A.: Software Development Process Model And Methodology For Virtual Laboratories. In: Proc. of the 20th IASTED Int. Multi-Conf. Applied Informatics, pp. 47-52 (2002)

16. Silver, M.S.: Decisional Guidance for Computer-Based Decision Support. MIS Quarterly $15,105-122$ (1991)

17. Todd, P., Benbasat, I.: Evaluating the Impact of DSS, Cognitive Effort, and Incentives on Strategy Selection. Information Systems Research 10, 356-374 (1999)

18. Scherp, A., Eißing, D., Staab, S.: strukt-A Pattern System for Integrating Individual and Organizational Knowledge Work. In: Aroyo, L., Welty, C., Alani, H., Taylor, J., Bernstein, A., Kagal, L., Noy, N., Blomqvist, E. (eds.) ISWC 2011, Part I. LNCS, vol. 7031, pp. 569-584. Springer, Heidelberg (2011)

19. Scherp, A., Staab, S.: Analysis and Comparison of Models for Individual and Organizational Knowledge Work. In: Proceeding of Mulitkonferenz Wirtschaftsinformatik (2012)

20. Delone, W.H., McLean, E.R.: The DeLone and McLean Model of Information Systems Success: A Ten-Year Update. Journal of Management Information Systems 19, 9-30 (2003)

21. Wixom, B.H., Todd, P.A.: A Theoretical Integration of User Satisfaction and Technology Acceptance. Information Systems Research 16, 85-102 (2005) 